\author{
Benoît P. Guery \\ Maiken C. Arendrup \\ Georg Auzinger \\ Élie Azoulay \\ Márcio Borges Sá \\ Elizabeth M. Johnson \\ Eckhard Müller \\ Christian Putensen \\ Coleman Rotstein \\ Gabriele Sganga \\ Mario Venditti \\ Rafael Zaragoza Crespo \\ Bart Jan Kullberg
}

\section{Received: 9 October 2008}

Accepted: 9 October 2008

Published online: 30 October 2008

(C) The Author(s) 2008. This article is published with open access at

Springerlink.com

Part I is published at: doi:

10.1007/s00134-008-1338-7.

Electronic supplementary material

The online version of this article

(doi:10.1007/s00134-008-1339-6) contains

supplementary material, which is available to authorized users.

\section{B. P. Guery}

Infectious Diseases, SGRIVI,

Hopital Huriez, CHRU Lille,

59045 Lille Cedex, France

\section{C. Arendrup}

Unit of Mycology, Department

Bacteriology, Mycology and Parasitology,

Statens Serum Institut, Building 43/117,

2300 Copenhagen, Denmark

\section{G. Auzinger}

Liver Intensive Care, Institute of Liver

Studies, King's College Hospital,

Denmark Hill, London SE5 9RS, UK

\section{É. Azoulay}

Service de Réanimation Médicale, Hôpital Saint-Louis, 1, avenue Claude-Bellefaux, 75010 Paris, France

M. Borges Sá

Sepsis Unit, Intensive Care Department, Hospital Son Llàtzer, Palma de Mallorca, Spain

\title{
Management of invasive candidiasis and candidemia in adult non-neutropenic intensive care unit patients: Part II. Treatment
}

E. M. Johnson

Mycology Reference Laboratory,

National Collection of Pathogenic Fungi,

The HPA Centre for Infections,

HPA South West Laboratory,

Myrtle Road, Kingsdown,

Bristol BS2 8EL, UK

\section{E. Müller}

Universitätsklinik für Anästhesiologie, Intensivmedizin und Schmerztherapie, Knappschaftskrankenhaus Bochum, Langendreer, Klinikum der RuhrUniversität, In der Schornau 23-25, 44892 Bochum, Germany

\section{Putensen}

Operative Intensivmedizin, Klinik und Poliklinik für Anästhesiologie und Operative Intensivmedizin, RheinischeFriedrich-Wilhelms Universität Bonn, Sigmund-Freud Str. 25, 53127 Bonn, Germany

\section{Rotstein}

Division of Infectious Diseases, University Health Network, Toronto General Hospital, NCSB 11-1212, 200 Elizabeth Street, Toronto,

ON, M5G 2C4, Canada

\section{G. Sganga}

Department of Surgery,

Division of General Surgery and

Organ Transplantation,

Policlinico 'A Gemelli',

Catholic University, Largo Gemelli, 8, 00168 Rome, Italy

\section{Venditti}

Internal Medicine, Clinical Medicine Department, "La Sapienza" University, Rome, Viale dell' Università, 37, 00185 Rome, Italy
R. Zaragoza Crespo

Secretario GTEI-SEMICYUC, Medicina Intensiva, Hospital Universitario Dr. Peset, Avenida Gaspa Aguilar, 90, 46107 Valencia, Spain

\section{B. J. Kullberg (}

Department of Medicine (463),

Nijmegen Institute for Infection,

Inflammation, and Immunity (N4i),

Radboud University Nijmegen Medical

Centre, PO Box 9101, 6500 HB Nijmegen,

The Netherlands

e-mail: b.kullberg@aig.umcn.nl

Tel.: +31-24-3668015

Fax: +31-24-3541734

\begin{abstract}
Background: Invasive candidiasis and candidemia are frequently encountered in the nosocomial setting particularly in the intensive care unit (ICU). Objective and methods: To review the current management of invasive candidiasis and candidemia in non-neutropenic adult ICU patients based on a review of the literature and an European expert panel discussion. Results and conclusions: Empiric and directed treatment for invasive candidiasis are predicated on the hemodynamic status of the patient. Unstable patients may benefit from broad-spectrum antifungal agents, which can be narrowed once the patient has stabilized and the identity of the infecting species is established. In stable patients, a more classical approach using fluconazole may be satisfactory provided that the patient is not colonized
\end{abstract}


with fluconazole resistant strains or there has been recent past exposure to an azole ( $<30$ days). In contrast, preemptive therapy is based on the presence of surrogate markers.

Keywords Antifungal - Azole . Candida . Candidiasis .

Echinocandins - Invasive candidiasis . Intensive care $\cdot$ Polyenes

\section{Abbreviations \\ aPTT Activated partial thromboplastin time} CAGT Candida albicans germ tube CI Colonization index SDD

DLY Discounted life year

$\mathrm{FIO}_{2}$

$\mathrm{HwP1}$

ICU

INR

MAP

OR

$\mathrm{PaO}_{2}$

PCR

SBP
Fraction of inspired oxygen

Hyphal wall protein 1

Intensive care unit

International normalized

ratio

Mean arterial blood pressure

Odds ratio

Partial pressure of arterial

oxygen

Polymerize chain reaction

Systolic blood pressure
SD Standard deviation

SDD Selective digestive decontamination

SICU Surgical intensive care unit

SIRS Systemic inflammatory

response syndrome

$\mathrm{SvO}_{2} \quad$ Mixed venous oxygen

saturation

White blood cell

\section{Introduction}

The treatment of invasive candidiasis and candidemia can be schematically described as prophylactic, pre-emptive, empiric or curative. Prophylactic treatment covers all the situations where the patient is not infected and lacks the signs and symptoms of infection. In pre-emptive treatment, based on evaluation of the patient's risk factors combined with positive surrogate markers of infection, the patient is deemed to be at significant risk of being infected and this increased risk justifies a treatment; the goal is to decrease Candida-related mortality. Empiric therapy describes individuals with symptoms of infection with no obvious source who merit therapy based on clinical grounds. In many studies the lines between the latter two groups of treatment are not always very clear. Finally, curative treatment focuses on a microbiologically documented pathogen.

\section{The need for appropriate and early treatment}

Appropriate therapy is a major factor associated with a good prognosis in fungal infection. In a 5-year study, 207 patients were diagnosed with invasive candidiasis and candidemia of which $52 \%$ were due to Candida albicans [1], $64(32 \%)$ were given empirical therapy, of which 51 (26\%) was deemed adequate. Adequate empirical therapy was independently associated with a reduced risk of death (crude mortality rate 27 vs. 46\%; OR 0.46). A study performed in 28 hospitals in Spain showed that early therapy (treatment started within the $48 \mathrm{~h}$ after the onset of candidemia) was associated with a higher probability of survival [2]. In another study, Garey et al. [3] also emphasized the importance of the timing of treatment. In this study, mortality rates were lower for patients who began therapy on day $0(15 \%)$ compared to day 1 (24\%), day $2(37 \%)$ or later $(41 \%)$. The delay was defined as the difference between blood drawing and treatment onset. A comparable result was found by Morrell et al. [4]: in this study, the authors showed that administration of antifungal treatment $12 \mathrm{~h}$ after having the first positive blood sample for culture was an independent marker of hospital mortality. In non-neutropenic critically ill patients with sepsis, inappropriate empirical antimicrobial therapy was frequently associated with presence of invasive fungal infection and contributed to an increased mortality rate [5]. Kumar et al. also demonstrated increased mortality rates in patients with fungal sepsis and shock associated with delays in the initiation of therapy: every hour delay was associated with a $12 \%$ decreased probability of survival $[1,6]$.

\section{Prophylactic antifungal treatment in the ICU}

Candida spp live as commensals in the gut lumen and on cutaneous surfaces. As has been previously discussed, there is a strong link between Candida colonization and invasive candidiasis; therefore it would seem clinically relevant to decrease the fungal load with an antifungal drug. Since morbidity and mortality rates in patients with invasive candidiasis infections are high, the use of prophylaxis seems very attractive. This prophylactic strategy has been validated in different subsets of patients such as neutropenic patients with hematological malignancies, or after bone marrow transplant [7]. In the ICU, this approach remains under discussion. There is a need to better identify the ICU patient profile that could benefit from prophylactic antifungal therapy as the following studies illustrates.

In a medical/SICU, Garbino et al. [8] compared two groups of patients with selective digestive decontamination (SDD) with or without fluconazole (100 mg daily). 
Their results showed that $90 \%$ of candidemia episodes occurred in the placebo group, but the crude mortality rate remained unchanged. In selected high-risk surgical patients undergoing relaparotomy for bowel perforation or suture leakage, Eggimann et al. [9] used intravenous fluconazole prophylaxis and showed prevention of both colonization and invasive intra-abdominal invasive candidiasis. An important observation in this study, compared to the previously described Garbino trial, is the dose of fluconazole used (400 mg daily), which was a curative rather than a prophylactic dose. Moreover, it is difficult to know, from the type of patients recruited, whether it was genuine prophylactic treatment as the study mostly involved a high-risk surgical population. Hence applying current criteria the study may be better described as evaluating pre-emptive or empirical treatment. This approach is further supported by data from Pelz et al. [10] who showed in a prospective study of 159 ICU patients that fungal burden was strongly associated with infection. In this trial, having two or more sites positive in a single day was associated with an odd ratio of 8.2. Recently, Manzoni et al. [11] showed a significant decrease of invasive candidiasis with fluconazole prophylaxis, although this was in neonates; no effect on mortality was observed.

A systematic review of published antifungal prophylaxis studies carried out in the ICU setting evaluated whether systematic antifungal therapy could decrease morbidity and mortality [12]. Prophylaxis with an azole was associated with a reduced rate of candidemia, as well as a decrease of Candida-attributable mortality and overall mortality rates. While the systematic review was based on highly divergent studies, addressing different methodologies, different patient populations and using different antifungal therapy, the conclusions of this review nevertheless lend some support to the hypothesis that prophylaxis could be of benefit in selected subsets of patients. The results of five meta-analyses on this subject are nicely summarized in a review paper by Pfaller et al. [13] and support a policy of prophylaxis in selected patients, with a reduction of the risk of invasive form by 50 to $80 \%$. The effect was however, less clear on mortality or on the emergence of azole-resistant Candida species. The selection of patient groups who will benefit from prophylaxis is still unclear, and there is a need for additional data.

Prophylactic therapy should also be scrutinized in relation to potential deleterious consequences such as selection of resistant strains and drug-related toxicity [14]. Several studies have suggested a potential link between prophylactic use of fluconazole and an increase in resistance or selection of azole-resistant species. Bassetti et al. [15] observed this phenomenon during a 5 -year study from Brazil. Interestingly, although not strictly confined to ICU patients, a retrospective study attempted to describe all cases of nosocomial candidemia that occurred in patients receiving at least 3 days of systemic antifungal drugs [16]. Non-albicans species, mainly C. parapsilosis, and C. tropicalis, the two most prevalent non-albicans Candida species in this country, caused $75 \%$ of these infections. Of the 20 patients studied, $40 \%$ had cancer, and when compared to controls, risk factors were mucositis, longer stay in the ICU, longer periods of hyperalimentation, mechanical ventilation, urinary catheter, and use of broad-spectrum antibiotics. Similarly, one case report documented a C. glabrata isolate with a specific profile of resistance in a critically ill patient, that was resistant to both amphotericin B and caspofungin [17]. In a retrospective analysis of two ICU patient cohorts, Rocco et al. [18] analyzed the effect of fluconazole administration on Candida sensitivity. As use of this antifungal agent increased, an increase in Candida spp that were resistant to fluconazole was observed.

\section{Empiric and pre-emptive treatments}

Several drugs have been tested in these settings and could therefore be proposed for treatment. A retrospective audit of 225 SICU patients receiving antifungal therapy showed that fluconazole was the most frequently prescribed antifungal drug (1,846 patient-days), followed by amphotericin B (251 patient-days) [19]. These data are not representative of current usage patterns as the study was carried out between 2001 and 2002. The drugs were prescribed empirically (44\%), for pre-emptive therapy in colonized patients $(43 \%)$ or in those with candidiasis (12\%). The authors concluded that efforts to identify patients who warrant pre-emptive antifungal therapy for invasive candidiasis could dramatically change antifungal prescribing patterns in this setting. However, there are no substantiating data from randomized trials to support the empiric or pre-emptive use of antifungal agents in the ICU setting.

Piarroux et al. [20] tried to assess the efficacy of preemptive antifungal therapy in preventing proven candidiasis in critically ill surgical patients. In a total of 933 patients, they evaluated, as a primary endpoint, the frequency of proven candidiasis within a prospective period during which patients with a corrected colonization index $\geq 0.4$ received early pre-emptive antifungal therapy with fluconazole. Candida infections occurred more frequently in the control cohort ( 7 vs. $3.8 \% ; P=0.03$ ). The incidence of SICU-acquired proven candidiasis significantly decreased from 2.2 to $0 \%$. The authors concluded that a targeted pre-emptive strategy may be effective in preventing acquisition of proven candidiasis in SICU patients. 


\section{Treatment of documented infection}

In recent guidelines the drugs proposed as first-line therapy have usually been selected based on the clinical status of the patient $[14,21]$. The reason for such risk-based strategy is the assumption that critically-ill patients may benefit most from a highly-active therapy, and that there is no room for failure. If narrow-spectrum antifungals are chosen they may not cover the pathogen involved. This hypothesis may be supported by the recent studies suggesting that early institution of adequate antifungal therapy may significantly reduce mortality in patients with candidemia, as described above $[3,4,6]$. Thus although this is not evidenced based medicine, retrospective data point to a differentiation between hemodynamically stable from hemodynamically unstable patients. It can be assumed that a clear line can be drawn for patients in septic shock, an intermediate risk group should be proposed for patients with severe sepsis. It seems appropriate therefore, to first describe the specific definitions before discussing the treatment itself.

Systemic inflammatory response syndrome, sepsis, severe sepsis and septic shock

After its initial definition in 1991, the diagnosis of sepsis was revisited in 2003 and the list of clinical signs and symptoms was expanded, reflecting bedside experience [22]. The definition of a hemodynamically unstable patient with sepsis needs to be applied according to this classification. Four stages are differentiated: systemic inflammatory response syndrome (SIRS), sepsis, severe sepsis (with organ dysfunction), and septic shock.

Sepsis is defined by the presence of both infection and SIRS. The diagnostic criteria for sepsis are summarized in the Electronic supplement material. Severe sepsis refers to sepsis complicated by organ dysfunction, and septic shock represents a state of acute circulatory failure characterized by persistent arterial hypotension despite adequate volume resuscitation in the absence of other causes of hypotension.
A patient with septic shock is clearly characterized as a hemodynamically unstable patient; SIRS and sepsis patients however, do not fit this definition. Most of the debate or controversy regarding the identification of hemodynamically unstable patients focuses on the patient with severe sepsis, i.e. a patient with organ failure. They are at higher risk of progressing to septic shock if treatment is inadequate. Although they do not completely fit the definition of 'hemodynamically unstable', it may be prudent to classify these patients as high-risk and therefore propose a line of treatment identical to that for the well-defined unstable group using additional markers like plasma lactate.

The available drugs and their main treatment outcomes in the ICU

Treatment of invasive candidiasis and candidemia has changed significantly in recent years due to a growing number of newly available agents, and the resulting modification of guidelines. Case series, published in the 1990s, used mainly fluconazole and amphotericin B and showed no difference between the two groups [2]. The main concern with amphotericin B was its toxicity.

Currently available drugs to treat invasive candidiasis and candidemia include amphotericin B and its derived lipid formulations, fluconazole, voriconazole, caspofungin, anidulafungin and micafungin. The focus of this review will be on data from the most recently introduced agents-caspofungin, anidulafungin and voriconazole. Most Candida spp are usually susceptible to these agents, but resistance has been described either naturally or after previous exposure to the drugs. For example, C. glabrata, C. krusei, C. parapsilosis and C. lusitaniae can present resistance to the primary agent or require a dosage increase (Table 1).

Echinocandins are the most recently introduced class of antifungal drugs. This new class includes caspofungin, anidulafungin, both now available in Europe, and micafungin, which is not yet marketed. Echinocandins are fungicidal drugs that are active against both $C$. albicans

Table 1 Minimum inhibitory concentration (50/90\%) of antifungal agents against the most common Candida species

\begin{tabular}{|c|c|c|c|c|c|c|c|c|c|c|c|c|}
\hline & \multicolumn{2}{|c|}{$\begin{array}{l}\text { Amphotericin B } \\
(\mu \mathrm{g} / \mathrm{ml})[44]\end{array}$} & \multicolumn{2}{|c|}{$\begin{array}{l}\text { Flucytosine } \\
(\mu \mathrm{g} / \mathrm{ml})[44]\end{array}$} & \multicolumn{2}{|c|}{$\begin{array}{l}\text { Fluconazole } \\
(\mu \mathrm{g} / \mathrm{ml})[44]\end{array}$} & \multicolumn{2}{|c|}{$\begin{array}{l}\text { Voriconazole } \\
(\mu \mathrm{g} / \mathrm{ml})[44]\end{array}$} & \multicolumn{2}{|c|}{$\begin{array}{l}\text { Caspofungin } \\
(\mu \mathrm{g} / \mathrm{ml})[44]\end{array}$} & \multicolumn{2}{|c|}{$\begin{array}{l}\text { Anidulafungin } \\
(\mu \mathrm{g} / \mathrm{ml})[44]\end{array}$} \\
\hline & $\mathrm{MIC}_{50}{ }^{\mathrm{c}}$ & $\mathrm{MIC}_{90}^{\mathrm{c}}$ & $\mathrm{MIC}_{50}^{\mathrm{c}}$ & $\mathrm{MIC}_{90}^{\mathrm{c}}$ & $\mathrm{MIC}_{50}^{\mathrm{c}}$ & $\mathrm{MIC}_{90}^{\mathrm{c}}$ & $\mathrm{MIC}_{50}^{\mathrm{c}}$ & $\mathrm{MIC}_{90}^{\mathrm{c}}$ & $\mathrm{MIC}_{50}^{\mathrm{c}}$ & $\overline{M^{\prime} C_{90}^{c}}$ & $\mathrm{MIC}_{50}^{\mathrm{c}}$ & $\mathrm{MIC}_{90}^{\mathrm{c}}$ \\
\hline C. albicans & 0.06 & 0.25 & 0.13 & 1 & 0.25 & 2 & 0.03 & 0.06 & 0.5 & 0.5 & 0.03 & 0.03 \\
\hline C. glabrata & 0.13 & 0.5 & 0.13 & 0.13 & 8 & 32 & 0.25 & 1 & 0.5 & 1 & 0.03 & 0.13 \\
\hline C. parapsilosis & 0.1 & 0.5 & 0.13 & 0.13 & 1 & 2 & 0.03 & 0.06 & 2 & 2 & 2 & 2 \\
\hline C. tropicalis & 0.13 & 0.5 & 0.13 & 0.5 & 0.5 & 16 & 0.06 & 2 & 0.5 & 1 & 0.03 & 0.13 \\
\hline C. krusei & 0.25 & 0.5 & 4 & 32 & 32 & $>64$ & 0.5 & 1 & 1 & 2 & 0.06 & 0.13 \\
\hline C lusitaniae & 0.13 & 0.5 & 0.13 & 0.13 & 0.5 & 2 & 0.03 & 0.06 & 1 & 2 & 0.06 & 0.25 \\
\hline
\end{tabular}


and non-albicans species. Caspofungin has been shown to be as effective as, and better tolerated than, conventional amphotericin B in patients with invasive candidiasis [23]. This improvement in tolerance could be important in the management of the ICU patient, particularly in those with renal failure. Evaluation of this drug in ICU patients has been carried out in a post hoc analysis of the Mora-Duarte trial [23] specifically in relation to risk factors and outcome. The authors found that even after accounting for differences in the Apache II score, patients starting the study drug in the ICU were more likely to die than those starting it outside the ICU [24]. The all-cause mortality among candidemic ICU patients was $45 \%$. There was no statistically significant difference in all-cause or Candidaattributable mortality rate between patients treated with either caspofungin or amphotericin B, but the incidence of drug-related adverse events and of nephrotoxicity was significantly lower in the caspofungin group. These findings suggest that caspofungin could be an attractive choice in ICU patients in whom renal failure or prior azole exposure limit the use of other antifungal agents. It must however be underlined that, beside toxicity, the efficacy between the two drugs showed no significant differences. Pappas et al. [25] compared two dosages of micafungin to caspofungin. The results showed that $100 \mathrm{mg}$ daily and $150 \mathrm{mg}$ daily were non-inferior to a standard dosage of caspofungin for the treatment of candidemia. The authors did not find any statistical difference in mortality, relapsing and emergent infection or adverse events between the drugs. Of note, whereas micafungin has been licensed, its approved use in Europe is restricted to cases where other antifungals are not appropriate, in view of its potential risk for the development of liver tumors. Table 2 summarizes the main results of the studies involving echinocandins.

It has been shown, mostly through study of antibiotics, that the pharmacokinetic/pharmacodynamic profile of ICU patients is different from that of non-ICU controls, with large variations in the volume of distribution and renal clearance. Nguyen et al. [26] analyzed the factors influencing caspofungin concentrations in ICU patients; they showed that body weight $<75 \mathrm{~kg}$ and albumin concentration $>23.6 \mathrm{~g} / \mathrm{l}$ was associated with higher levels of caspofungin than predicted.

Anidulafungin has recently been studied in a randomized double blind trial of treatment for invasive candidiasis [21]. In this study, anidulafungin was compared with fluconazole, with the primary efficacy analysis assessing the global response at the end of intravenous therapy. At this endpoint, treatment was successful in $75.6 \%$ of patients treated with anidulafungin, as compared with $60.2 \%$ of those treated with fluconazole $(P=0.009)$. In this population, $21 \%$ in the anidulafungin group and $17 \%$ in the fluconazole group had an Apache II score $>20$. Overall, the authors concluded that anidulafungin was not inferior to and suggested to be more efficacious than fluconazole for the primary treatment of candidemia, with a safety profile similar to that of fluconazole. The authors also commented that the success rate at the end of intravenous anidulafungin in this trial was similar to that reported in a study evaluating caspofungin in the primary treatment of invasive candidiasis [23].

There are also new azoles that should be considered for therapy of invasive candidiasis in ICU patients. Voriconazole is recommended as first-line of therapy in invasive aspergillosis, but several studies suggest a potential role in candidiasis. Ostrosky-Zeichner et al. [27] showed that voriconazole was efficient as a salvage therapy in this indication. In a randomized study in nonneutropenic patients with candidemia, voriconazole was compared to a regimen of amphotericin B followed by fluconazole [28]. Half of the patients in each group were in the ICU. The results showed that voriconazole was as effective as the control regimen in the treatment of candidemia, with significantly fewer side-effects. In this study, amphotericin B was only administered for a median of 4 days, underlining that even short courses of this drug could be associated with significant adverse effects. One limitation regarding extrapolation of voriconazole use for ICU patients is that the i.v. formulation of

Table 2 Main studies in non neutropenic patients evaluating echinocandins in invasive candidemia

\begin{tabular}{|c|c|c|c|c|c|c|c|}
\hline $\begin{array}{l}\text { Author } \\
\text { (references) }\end{array}$ & Year & $\begin{array}{l}\text { Antifungal } \\
\text { agents }\end{array}$ & $\begin{array}{l}\text { No of } \\
\text { patients }\end{array}$ & $\begin{array}{l}\text { Success }^{\mathrm{a}} \\
(\mathrm{mITT}) \%\end{array}$ & $\begin{array}{l}\text { Success for Apache } \\
\text { II }>20 n(\%)\end{array}$ & $\begin{array}{l}\text { Crude } \\
\text { mortality }(\%)\end{array}$ & $\mathrm{AE}(\%)$ \\
\hline \multirow[t]{2}{*}{ Mora-Duarte [23] } & \multirow[t]{2}{*}{2002} & Amphotericin B & 125 & 61.7 & $10 / 23(43.5)$ & 30.4 & 75.2 \\
\hline & & Caspofungin & 114 & 73.4 & $12 / 21(47.1)$ & 34.2 & 42.1 \\
\hline \multirow{2}{*}{ Reboli [21] } & \multirow{2}{*}{2007} & Anidulafungin & 127 & 75.6 & \multirow{2}{*}{ No difference between the groups } & 22.8 & 24.4 \\
\hline & & Fluconazole & 118 & 60.2 & & 31.4 & 26.4 \\
\hline \multirow[t]{2}{*}{ Kuse } & \multirow[t]{2}{*}{2007} & Micafungin & 247 & 74.1 & $31 / 39(79.5)$ & 18 & 43.2 \\
\hline & & LFAB & 247 & 69.6 & $33 / 37(89.2)$ & 17 & 50.9 \\
\hline \multirow[t]{3}{*}{ Pappas [25] } & \multirow[t]{3}{*}{2007} & Micafungin 100 & 191 & 76.4 & $21 / 35(60)$ & 29 & 22 \\
\hline & & Micafungin 150 & 199 & 71.4 & $22 / 40(55)$ & 33.2 & 22.8 \\
\hline & & Caspofungin & 188 & 72.3 & $21 / 36(58.3)$ & 26.4 & 23.8 \\
\hline
\end{tabular}

mITT Modified intention to treat, EOT end of treatment, $A E$ adverse event, $L F A B$ lipid formulations of amphotericin B

${ }^{\text {a }}$ Success evaluated at the end of IV therapy 
voriconazole is contra-indicated in patients with a creatinine clearance of $<50 \mathrm{ml} / \mathrm{min}$.

Antifungal therapy based on patient's clinical status

A treatment algorithm for invasive candidiasis was recently proposed by Spellberg et al. [29]. They proposed the hemodynamic status of the patient as the main criterion for selection of pharmacological intervention (Fig. 1).

In hemodynamically stable patients without organ dysfunction, fluconazole is a reasonable choice for empiric therapy or microbiologically documented infection, based on its highly favorable safety profile and low costs [30]. Alternative drugs to be considered are echinocandins (caspofungin or anidulafungin), voriconazole, or amphotericin B (deoxycholate or liposomal). The duration of treatment should be continued for 2 weeks after the last positive culture.

However, if the likelihood of azole-resistant species is high, based on local resistance reports, if the patient is colonized with azole-resistant species, or recently exposed to an azole (within 30 days) as prophylactic



Fig. 1 Algorithm summarizing the practical treatment of documented candidiasis in the ICU. $L F A B$ Liposomal form of amphotericin B treatment, fluconazole should be avoided and the use of echinocandins or polyenes is preferred.

In contrast, patients who are hemodynamically unstable with septic shock or who have signs of severe sepsis require potent therapy, with a broad-spectrum agent that has a minimum toxicity. To achieve this aim, echinocandins are a preferred first choice (caspofungin or anidulafungin), as has been supported by the results of the Reboli study [21]. Alternatively, lipid formulations of amphotericin B (LFAB) may be used in unstable patients. Conventional amphotericin B is associated with a high risk of side effects e.g. renal failures and can therefore not be recommended in critically ill patients. Transition from an echinocandin or LFAB to fluconazole or voriconazole is recommended once patients are clinically stabilized and the isolate has been confirmed to be azole-susceptible.

\section{Combination therapy}

The poor prognosis attributed to Candida sepsis in the ICU has provoked much debate on the potential beneficial effect of combination therapy, but currently few studies have been conducted in this area. In a study comparing fluconazole with amphotericin B versus fluconazole alone, the combination resulted in a better response rate in the combination group, although associated with significant amphotericin B toxicity [31]. Flucytosine is another classical agent used in combined therapy; because of its ability to penetrate the blood brain barrier, this drug is often added to amphotericin in cerebral, ocular and meningeal localizations [32, 33]. Over many years different studies have described multiple antifungal combinations for the treatment of invasive fungal infections. The scientific rationale to support the use of combination therapy is based on the hypothesis that the infecting pathogen is more effectively treated if drugs with different mechanisms of action are combined. Recently, one study on Aspergillus infection in transplant patients obtained better results with voriconazole plus caspofungin compared with lipid formulation of amphotericin B [34]. To date, the use of combination antifungal therapy in patients with invasive candidiasis is not recommended and further studies are required.

\section{Cost-effectiveness of these approaches}

In a cost-effectiveness analysis concerning ICU patients, Golan et al. [35] showed that in suspected infections that have not responded to antibiotic treatment, empirical fluconazole could reduce mortality at an acceptable cost. They also concluded that empirical strategies are not justified in low-risk patients. Recent work by Chen et al. [36] further developed this approach by using a high dose 
of fluconazole in ICU patients suspected to have invasive candidiasis. The rationale for this approach was the observed increasing percentage of non-albicans Candida with a decreased susceptibility to fluconazole. In this study, high-dose fluconazole was the more effective but also more expensive treatment strategy compared to lowdose therapy, with a cost-effectiveness rate of $\$ 55,526$ per discounted life year (DLY) saved. The authors concluded that this strategy should reduce mortality at an acceptable cost. However, it should be noted that these models have not taken into account the results of the recent study suggesting a significantly better outcome with anidulafungin compared with fluconazole [21] which would justify a formal cost-effectiveness analysis comparing anidulafungin with fluconazole-based strategies.

\section{Catheter management in the ICU patient}

It has been known for a long time that intravascular catheters are significant risk factors for the development of candidemia [37, 38]. The initial retrospective study by Rex et al. [39] suggested the need to remove all intravascular catheters in candidemia. In the subset of patients who had a catheter in place at the time of their first positive blood culture, removal and replacement of all lines was associated with a reduction in the mean duration of candidemia. In a study performed in cancer patients, central venous catheter removal was only effective in improving the response to antifungal agents when the candidemia could be related to the catheter [40]. In ICU patients, however, it seems reasonable to propose catheter exchange in all patients with candidemia whenever logistically feasible.

\section{Pharmacokinetics profile}

The pharmacokinetics properties of an antimicrobial agent are essential to promote microbiological eradication and clinical efficacy. ICU patients with invasive Candida infections present special characteristics: higher disease severity, organ dysfunction (particularly in case of cardiovascular, renal and hepatic failure), co-morbidities and drugs. In these patients, not only plasma concentrations but also tissue penetration of the antifungal drug is crucial to obtain favorable clinical and microbiological results. The pharmacokinetic analyses of echinocandins suggest that these drugs behave like concentration-dependent molecules, thus high intermittent dosing may be desirable for the treatment of invasive candidiasis. The potential limitations of high drug doses include a paradoxical decrease in microbial kill (the eagle effect) as well as the toxicity of high intermittent doses [41]. Finally the main difference between caspofungin, micafungin, and anidulafungin relates on the elimination profile, the half life and the distribution volume [42]. Additional pharmacokinetics studies are needed in ICU patients [43].

\section{Conclusion}

The choice of empiric therapy or therapy for documented infection is dependent on the hemodynamic status of the patient, and will probably involve the use of drugs from the echinocandin family if the patient is unstable. On the other hand, a stable patient can be treated with azole as long as known colonization with a fluconazole-resistant strain, local epidemiology or previous exposure to this drug does not demand a broader antifungal spectrum. Current guidelines have to be re-evaluated as the availability of new molecules, new tests and new diagnostic procedures, raise important questions that have to be answered, specifically in this subset of patients.

\section{Expert opinion}

Intensive care unit patients represent a diverse population for the treatment of invasive candidiasis; the clinical presentation and vital prognosis are usually the key issues of the treatment. According to the current literature, the use of prophylactic therapy in high-risk individuals such as surgical ICU patients warrants consideration. In documented Candida infection and those patients highly suspected of having invasive candidiasis, the choice of therapy depends on the hemodynamic status of the patient and previous azole exposure or resistance. In the hemodynamically unstable patient, a broad spectrum fungicidal drug like an echinocandin is the preferred choice. Since the diagnosis of invasive candidiasis occurs in the late phase of the evolution of the disease (either a positive blood culture, or a high colonization index for example), the main challenge for the future is to elaborate diagnostic methods that will give us the opportunity to identify the patients affected by these infections earlier in the course of the disease. Moreover, beyond diagnosis correct identification of the pathogen and its associated resistance pattern needs to be improved. Finally, in ICU patients, combination antifungal therapy remains to be explored.

Conflict of interest Benoit Guery was consultant for GSK, Wyeth, and Pfizer. Maiken C. Arendrup received honoraries as a speaker from Astellas, MSD, Swedish Orphan, Pfizer, Schering Plough and Cephalon and a research grant from Pfizer, and Schering Plough. Georg Auzinger received honoraria from Pfizer for advisory activities. Elie Azoulay has received research grants from Pfizer France and honorarium for lectures from Pfizer and Gilead. Marcio Borges Sá received honoraries as a speaker from MSD, Cephalon, Pfizer, Astra-Zeneca and Wyeth. Elisabeth Johnson received speakers honoraria from Gilead, MSD, Pfizer and Schering Plough, 
consultant honoraria from Gilead, MSD, Pfizer and Schering Plough and research funding from Gilead. Eckhard Müller was speaker and received consultation fees for Astra Zeneca, SanofiAventis Germany, Bayer Vital, Biosyn Arzneimittel, Biotest AG, Fresenius Medical Care, MSD Sharp \& Dohme, Novartis Pharma, Pfizer Pharma, Wyeth Pharma and participated to Advisory Boards of Caspofungin (Fa. MSD Sharp \& Dohme GmbH; Merck, USA), Voriconazol (Fa. Pfizer Pharma $\mathrm{GmbH}$ ), Anidulafungin (Fa. Pfizer, Germany; Fa. Pfizer, Europa), and Posaconazol (Fa. Essex Pharma, invited). Coleman Rotstein received Grants/Research Supports from Astellas, Basilea, Johnson \& Johnson, Merck, Pfizer, Wyeth; was consultant for Astellas, Bayer, Merck, Pfizer, Wyeth and belonged to the speakers Bureau of Bayer, Merck, Pfizer, Wyeth. Gabriele Sganga received honoraries as a speaker from Pfizer,
Gilead and Wyeth. Mario Venditti received honoraries as a speaker from Angelini, Aventis, Bayer, Glaxo, Novartis, Pfizer, Wyeth and as a consultant from Novartis and Wyeth. Bart Jan Kullberg was consultant for Basilea, Novartis, and Pfizer. The other authors do not declare any conflict of interest.

Open Access This article is distributed under the terms of the Creative Commons Attribution Noncommercial License which permits any noncommercial use, distribution, and reproduction in any medium, provided the original author(s) and source are credited.

\section{References}

1. Parkins MD, Sabuda DM, Elsayed S, Laupland KB (2007) Adequacy of empirical antifungal therapy and effect on outcome among patients with invasive Candida species infections. J Antimicrob Chemother 60:613-618

2. Nolla-Salas J, Sitges-Serra A, Leon-Gil C, Martinez-Gonzalez J, Leon-Regidor MA, Ibanez-Lucia P, Torres-Rodriguez JM (1997) Candidemia in nonneutropenic critically ill patients: analysis of prognostic factors and assessment of systemic antifungal therapy. Study Group of Fungal Infection in the ICU. Intensive Care Med 23:23-30

3. Garey KW, Rege M, Pai MP, Mingo DE, Suda KJ, Turpin RS, Bearden DT (2006) Time to initiation of fluconazole therapy impacts mortality in patients with candidemia: a multi-institutional study. Clin Infect Dis 43:25-31

4. Morrell M, Fraser VJ, Kollef MH (2005) Delaying the empiric treatment of candida bloodstream infection until positive blood culture results are obtained: a potential risk factor for hospital mortality. Antimicrob Agents Chemother 49:3640-3645

5. Garnacho-Montero J, GarciaGarmendia JL, Barrero-Almodovar A, Jimenez-Jimenez FJ, Perez-Paredes C, Ortiz-Leyba C (2003) Impact of adequate empirical antibiotic therapy on the outcome of patients admitted to the intensive care unit with sepsis. Crit Care Med 31:2742-2751

6. Kumar A, Roberts D, Wood KE, Light B, Parrillo JE, Sharma S, Suppes R, Feinstein D, Zanotti S, Taiberg L, Gurka D, Kumar A, Cheang M (2006) Duration of hypotension before initiation of effective antimicrobial therapy is the critical determinant of survival in human septic shock. Crit Care Med 34:1589-1596
7. Hughes WT, Armstrong D, Bodey GP, Bow EJ, Brown AE, Calandra T, Feld R, Pizzo PA, Rolston KV, Shenep JL, Young LS (2002) 2002 guidelines for the use of antimicrobial agents in neutropenic patients with cancer. Clin Infect Dis 34:730-751

8. Garbino J, Lew DP, Romand JA, Hugonnet S, Auckenthaler R, Pittet D (2002) Prevention of severe Candida infections in nonneutropenic, high-risk, critically ill patients: a randomized, double-blind, placebo-controlled trial in patients treated by selective digestive decontamination. Intensive Care Med 28:1708-1717

9. Eggimann P, Francioli P, Bille J, Schneider R, Wu MM, Chapuis G, Chiolero R, Pannatier A, Schilling J, Geroulanos S, Glauser MP, Calandra T (1999) Fluconazole prophylaxis prevents intra-abdominal candidiasis in high-risk surgical patients. Crit Care Med 27:1066-1072

10. Pelz RK, Lipsett PA, Swoboda SM, Diener-West M, Hammond JM, Hendrix CW (2000) The diagnostic value of fungal surveillance cultures in critically ill patients. Surg Infect (Larchmt) 1:273-281

11. Manzoni P, Stolfi I, Pugni L, Decembrino L, Magnani C, Vetrano G, Tridapalli E, Corona G, Giovannozzi C, Farina D, Arisio R, Merletti F, Maule M, Mosca F, Pedicino R, Stronati M, Mostert M, Gomirato G (2007) A multicenter, randomized trial of prophylactic fluconazole in preterm neonates. N Engl J Med 356:2483-2495

12. Cruciani M, de Lalla F, Mengoli C (2005) Prophylaxis of Candida infections in adult trauma and surgical intensive care patients: a systematic review and meta-analysis. Intensive Care Med 31:1479-1487
13. Pfaller MA, Diekema DJ (2007) Epidemiology of invasive candidiasis: a persistent public health problem. Clin Microbiol Rev 20:133-163

14. Rex JH, Sobel JD (2001) Prophylactic antifungal therapy in the intensive care unit. Clin Infect Dis 32:1191-1200

15. Bassetti M, Righi E, Costa A, Fasce R, Molinari MP, Rosso R, Pallavicini FB, Viscoli C (2006) Epidemiological trends in nosocomial candidemia in intensive care. BMC Infect Dis 6:21

16. Pasqualotto AC, Nedel WL, Machado TS, Severo LC (2006) Risk factors and outcome for nosocomial breakthrough candidaemia. J Infect 52:216-222

17. Krogh-Madsen M, Arendrup MC, Heslet L, Knudsen JD (2006) Amphotericin B and caspofungin resistance in Candida glabrata isolates recovered from a critically ill patient. Clin Infect Dis 42:938-944

18. Rocco TR, Reinert SE, Simms HH (2000) Effects of fluconazole administration in critically ill patients: analysis of bacterial and fungal resistance. Arch Surg 135:160-165

19. Garey KW, Neuhauser MM, Bearden DT, Cannon JP, Lewis RE, Gentry LO, Kontoyiannis DP (2006) Evaluation of antifungals in the surgical intensive care unit: a multi-institutional study. Mycoses 49:226-231

20. Piarroux R, Grenouillet F, Balvay $P$, Tran V, Blasco G, Millon L, Boillot A (2004) Assessment of preemptive treatment to prevent severe candidiasis in critically ill surgical patients. Crit Care Med 32:2443-2449

21. Reboli AC, Rotstein C, Pappas PG, Chapman SW, Kett DH, Kumar D, Betts R, Wible M, Goldstein BP, Schranz J, Krause DS, Walsh TJ (2007) Anidulafungin versus fluconazole for invasive candidiasis. N Engl J Med 356:2472-2482 
22. Levy MM, Fink MP, Marshall JC, Abraham E, Angus D, Cook D, Cohen J, Opal SM, Vincent JL, Ramsay G (2003) $2001 \mathrm{SCCM} / \mathrm{ESICM} / \mathrm{ACCP} /$ ATS/SIS International Sepsis Definitions Conference. Crit Care Med 31:1250-1256

23. Mora-Duarte J, Betts R, Rotstein C, Colombo AL, Thompson-Moya L, Smietana J, Lupinacci R, Sable C, Kartsonis N, Perfect J (2002) Comparison of caspofungin and amphotericin B for invasive candidiasis. N Engl J Med 347:20202029

24. DiNubile MJ, Lupinacci RJ, Strohmaier KM, Sable CA, Kartsonis NA (2007) Invasive candidiasis treated in the intensive care unit: observations from a randomized clinical trial. J Crit Care 22:237-244

25. Pappas PG, Rotstein CM, Betts RF, Nucci M, Talwar D, De Waele JJ, Vazquez JA, Dupont BF, Horn DL, Ostrosky-Zeichner L, Reboli AC, Suh B, Digumarti R, Wu C, Kovanda LL, Arnold LJ, Buell DN (2007) Micafungin versus caspofungin for treatment of candidemia and other forms of invasive candidiasis. Clin Infect Dis 45:883-893

26. Nguyen TH, Hoppe-Tichy T, Geiss HK, Rastall AC, Swoboda S, Schmidt J, Weigand MA (2007) Factors influencing caspofungin plasma concentrations in patients of a surgical intensive care unit. J Antimicrob Chemother 60:100-106

27. Ostrosky-Zeichner L, Oude Lashof AM, Kullberg BJ, Rex JH (2003) Voriconazole salvage treatment of invasive candidiasis. Eur J Clin Microbiol Infect Dis 22:651-655

28. Kullberg BJ, Sobel JD, Ruhnke M, Pappas PG, Viscoli C, Rex JH, Cleary JD, Rubinstein E, Church LW, Brown JM, Schlamm HT, Oborska IT, Hilton F, Hodges MR (2005) Voriconazole versus a regimen of amphotericin B followed by fluconazole for candidaemia in non-neutropenic patients: a randomised non-inferiority trial. Lancet 366:1435-1442

29. Spellberg BJ, Filler SG, Edwards JE Jr (2006) Current treatment strategies for disseminated candidiasis. Clin Infect Dis 42:244-251
30. Bougnoux ME, Kac G, Aegerter P, d'Enfert C, Fagon JY (2008)

Candidemia and candiduria in critically ill patients admitted to intensive care units in France: incidence, molecular diversity, management and outcome. Intensive Care Med 34:292-299

31. Rex JH, Pappas PG, Karchmer AW, Sobel J, Edwards JE, Hadley S, Brass C, Vazquez JA, Chapman SW, Horowitz HW, Zervos M, McKinsey D, Lee J, Babinchak T, Bradsher RW, Cleary JD, Cohen DM, Danziger L, Goldman M, Goodman J, Hilton E, Hyslop NE, Kett DH, Lutz J, Rubin RH, Scheld WM, Schuster M, Simmons B, Stein DK, Washburn RG, Mautner L, Chu TC, Panzer H, Rosenstein RB, Booth J (2003) A randomized and blinded multicenter trial of high-dose fluconazole plus placebo versus fluconazole plus amphotericin B as therapy for candidemia and its consequences in nonneutropenic subjects. Clin Infect Dis 36:1221-1228

32. Darling K, Singh J, Wilks D (2000) Successful treatment of Candida glabrata endophthalmitis with amphotericin B lipid complex (ABLC). J Infect 40:92-94

33. Smego RA Jr, Perfect JR, Durack DT (1984) Combined therapy with amphotericin B and 5-fluorocytosine for Candida meningitis. Rev Infect Dis 6:791-801

34. Singh N, Limaye AP, Forrest G, Safdar N, Munoz P, Pursell K, Houston S, Rosso F, Montoya JG, Patton P, Del Busto R, Aguado JM, Fisher RA, Klintmalm GB, Miller R, Wagener MM, Lewis RE, Kontoyiannis DP, Husain S (2006) Combination of voriconazole and caspofungin as primary therapy for invasive aspergillosis in solid organ transplant recipients: a prospective, multicenter, observational study. Transplantation 81:320-326

35. Golan Y, Wolf MP, Pauker SG, Wong JB, Hadley S (2005) Empirical antiCandida therapy among selected patients in the intensive care unit: a cost-effectiveness analysis. Ann Intern Med 143:857-869
36. Chen H, Suda KJ, Turpin RS, Pai MP, Bearden DT, Garey KW (2007) Highversus low-dose fluconazole therapy for empiric treatment of suspected invasive candidiasis among high-risk patients in the intensive care unit: a costeffectiveness analysis. Curr Med Res Opin 23:1057-1065

37. Aliyu SH, Enoch DA, Abubakar II, Ali R, Carmichael AJ, Farrington M, Lever AM (2006) Candidaemia in a large teaching hospital: a clinical audit. QJM 99:655-663

38. Fraser VJ, Jones M, Dunkel J, Storfer S, Medoff G, Dunagan WC (1992) Candidemia in a tertiary care hospital: epidemiology, risk factors, and predictors of mortality. Clin Infect Dis 15:414-421

39. Rex JH, Bennett JE, Sugar AM, Pappas PG, Serody J, Edwards JE, Washburn RG (1995) Intravascular catheter exchange and duration of candidemia. NIAID Mycoses Study Group and the Candidemia Study Group. Clin Infect Dis 21:994-996

40. Raad I, Hanna H, Boktour M, Girgawy E, Danawi H, Mardani M, Kontoyiannis D, Darouiche R, Hachem R, Bodey GP (2004) Management of central venous catheters in patients with cancer and candidemia. Clin Infect Dis 38:11191127

41. Gumbo T (2007) Impact of pharmacodynamics and pharmacokinetics on echinocandin dosing strategies. Curr Opin Infect Dis 20:587-591

42. Wagner C, Graninger W, Presterl E, Joukhadar C (2006) The echinocandins: comparison of their pharmacokinetics, pharmacodynamics and clinical applications. Pharmacology 78:161177

43. Bellmann R (2007) Clinical pharmacokinetics of systemically administered antimycotics. Curr Clin Pharmacol 2:37-58

44. Ostrosky-Zeichner L, Rex JH, Pappas PG, Hamill RJ, Larsen RA, Horowitz HW, Powderly WG, Hyslop N, Kauffman CA, Cleary J, Mangino JE, Lee J (2003) Antifungal susceptibility survey of 2, 000 bloodstream Candida isolates in the United States. Antimicrob Agents Chemother 47:3149-3154 